Since the first development of recombinant DNA techniques by UCSF and Stanford University scientists in 1973, this powerful technology has found commercial application in medicine, food processing, and more recently, agriculture. This year U.S. growers planted 45 million acres of transgenic crops, including herbicide-tolerant, insect- and disease-resistant varieties. But the age of wonder crops comes with its own set of prob- lems. This issue of California Agriculture explores two of them: how privatization of proprietary rights to key biotechnology will affect public germplasm development, and how the problems of pest resistance may affect the long-term success of larvae-killing transgenic cotton.

We express special thanks to Guest Editors Peggy Lemaux and Trevor Suslow for their contributions to this issue.

\title{
UC contributes biotech breakthroughs
}

$\overline{\mathrm{R}}$ esearchers at UC are pioneering basic science and recombinant DNA technology in an array of agricultural and environmental sciences.

One recent advance that promises to improve human health has been UC Berkeley microbial biologist Bob Buchanan's exploitation of thioredoxin, a naturally occurring product, to make proteins such as those found in wheat and milk more easily digestible and less allergenic.

Thioredoxin not only alleviates symptoms for allergy sufferers, but may also

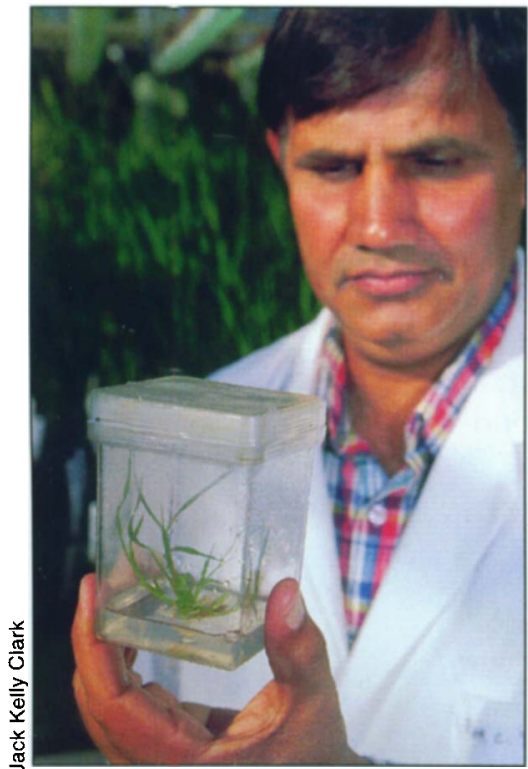

UC Davis geneticist Ram Chander Yadav examines a transgenic rice plant that he has created through Agrobacteriummediated transformation. He used the bacteria to transfer the resistance gene into the plant. help people with celiac disease, a disorder that causes the intestines to react abnormally to the gluten in wheat, rye, barley and oats.

Genetic engineering for disease resistance. Other UC scientists have genetically engineered plants to resist disease. For example, biotechnology specialist Peggy Lemaux's lab at UC Berkeley was the first to successfully genetically engineer barley, introducing viral genes to make it resistant to barley yellow dwarf virus.

UC Berkeley plant pathologist and microbial ecologist Steve Lindow developed the widely publicized "ice minus" bacteria that can be used to prevent frost and disease damage on crops. Based on his earlier genetic engineering studies, Lindow has developed a naturally occurring bacterial strain Pseudomonas fluorescens strain A506, commercially registered as Blightban A506 for use in California. It is most commonly used for fire blight and frost control in pears and apples.

A different gene-based approach to protecting crops is the focus of Brian Staskawicz's research. The UC Berkeley plant biologist and his lab team were the first to isolate a bacterial gene that triggers a defensive response in plants. This work has played a key role in discoveries of disease-resistance genes in plants. Aiso at UC Berkeley, plant geneticist Barbara Baker became the first person to clone a gene with natural resistance to viruses.

UC Davis plant pathologist Pamela Ronald, one of Staskawicz's former graduate students, has isolated and cloned a rice gene that resists the bacteria that cause blight, a devastating pestilence worldwide. Using this Xa21 gene, Ronald genetically engineered new blightresistant varieties of rice.

Genetic engineering for insect control. A research group at UC Davis, led by nematologist Valerie Williamson, discovered a resistance gene that is effective against both nematode and aphid. Williamson isolated the root-knot nematode-resistance gene Mi from tomato. Working with entomologist Diane Ullman, the group found that this same gene also confers resistance against potato aphids.

UC Davis entomologist Bruce Hammock's lab is working to incorporate genes into baculoviruses that control a critical insect hormone. The gene for a key enzyme that degrades the hormone has been isolated and sequenced by Hammock's lab, which is working to develop its use for biological insect control.

Baculovirus genes also confer resistance in plants. UC Davis plant pathologist David Gilchrist determined that programmed cell death, called apoptosis, plays a key role in plant infection. Apoptosis, an important process in genetic regulation and biochemical response of animals to disease, seems to fulfill a similar role in plants. To see if blocking apoptosis with a transgene would prevent disease in plants, Gilchrist and his colleagues inserted an anti- 
apoptotic gene from baculovirus into transgenic tomato plants and found that these plants were resistant to several diseases. Gilchrist hopes the merging of plant and animal research on apoptosis will lead to new methods for disease protection and enhanced food safety.

Meanwhile at UC Berkeley, plant biologist Sarah Hake was the first to clone a plant homeobox gene - pivotal genes that set up entire developmental pathways. In flies, for example, the incorrect expression of these genes has been shown to result in the formation of an eye on the thorax.

Postharvest applications for crops. USDA/ UC Berkeley Plant Gene Expression Center plant biologist Sakis Theologis was the first person to clone and characterize a critical gene in ethylene biosynthesis, which led to the creation of the Endless Summer tomato and the use of the technology to retard spoilage in other fruits and vegetables.

New techniques for remediating environmental contamination. UC Riverside chemical engineers Wilfred Chen and Ashok

Mulchandani recently engineered a bacterium that degrades organophosphate pesticides. The scientists designed a gene that directs the manufacture of a hybrid protein combining the enzyme organophosphorus hydrolase $(\mathrm{OPH})$ with other structures that anchor the $\mathrm{OPH}$ to the outer surfaces of bacterial cells. They then inserted the gene into a harmless strain of $E$. coli bacteria. Tested in parathion- and paraoxon-contaminated water, the new bacteria degraded the insecticides nine times more efficiently than bacteria with OPH located inside their cells.

Several naturally occurring bacteria can degrade polychlorinated biphenyls (PCBs) to chlorobenzoates, while others can degrade chlorobenzoates to water, carbon dioxide and sodium chloride (table salt). However, no single bacterium is able to perform the complete degradation of PCBs. UC Riverside plant pathologist Dennis Focht genetically engineered a microbe to clean up chlorobenzoates.

Using a method he patented last year, Focht is now creating these beneficial microbes naturally by introducing $P$ seudomonas aeruginosa, which degrade chlorobenzoates. Focht found that the indigenous Rhodococcus spp. bacteria, which provide the primary process of breaking down the PCBs, transfer the desired genes to the introduced bacteria, resulting in a more stable strain than the genetically engineered. "If nature can do it better, why not study how to optimize the natural process?" says Focht.

Approaches to modifying tree growth. UC Davis geneticists

Abhaya Dandekar and Gale McGranahan have modified walnut for improvement in root characteristics of the rootstock and bearing habit of the scion. Dandekar and McGranahan have taken genes from

Agrobacterium rhizogenes, which stimulates root production. They have introduced three genes - rol A, B and C - from the bacterium to Paradox trees, a common walnut rootstock variety. Field testing of the transgenic trees have shown that they are vigorous and more compact than nontransformed trees. - Editor

\section{Novartis commits $\$ \mathbf{2 5}$ million to UC Berkeley}

UC Berkeley and the Novartis Agricultural Discovery Institute, Inc., have agreed to create a unique long-term agricultural biotechnology research collaboration.

Under the terms of the agreement between Novartis and the Department of Plant and Microbial Biology in the College of Natural Resources, Novartis will commit \$25 million over 5 years to support basic research in the department in the area of agricultural genomics. It will also provide access to proprietary technology and DNA databases, which will significantly enhance the university's ability to do research at the forefront of plant genomics.

In return, Novartis scientists will work closely with UC Berkeley researchers, and the company will receive first rights to negotiate for a fraction - roughly $30 \%$ to $40 \%$ - of the discoveries made in the department. The fraction corresponds approximately to the proportion of the department's total research budget provided by Novartis, and will vary from year to year. Novartis, which was formed by the merger of Sandoz and Ciba-Geigy, will pay patent costs, license fees, royalties and all other costs normally associated with the commercialization of research, but the university will own the patents and collect royalties on their use.

Gordon Rausser, dean of the College of Natural Resources at UC Berkeley, says, "This is a valuable experiment, and we'll be monitoring it very closely to ensure that it produces synergies that enrich public interest research."

Among the safeguards is a six-member Advisory Committee to oversee the contract, made up of three UC Berkeley representatives and three Novartis representatives, as well as a five-member Research Committee to award the grants. The Research Committee will include three UC Berkeley faculty. 